\title{
Modified in vivo lung perfusion allows for prolonged perfusion without acute lung injury
}

\author{
Pedro Reck dos Santos, MD, ${ }^{\mathrm{a}, \mathrm{b}}$ Ilker Iskender, MD, ${ }^{\mathrm{a}, \mathrm{b}}$ Tiago Machuca, MD, ${ }^{\mathrm{a}}$ David Hwang, MD, \\ Marc dePerrot, MSc, MD, ${ }^{\mathrm{a}, \mathrm{b}}$ Mingyao Liu, MD, ${ }^{\mathrm{a}, \mathrm{b}}$ Shaf Keshavjee, MSc, MD, ${ }^{\mathrm{a}, \mathrm{b}}$ \\ Thomas K. Waddell, MSc, MD, PhD, ${ }^{a, b}$ and Marcelo Cypel, MSc, MD ${ }^{\mathrm{a}, \mathrm{b}}$
}

\begin{abstract}
Objectives: In vivo lung perfusion (IVLP) is an emergent strategy to treat lung metastases because it allows localized delivery of chemotherapy with minimal systemic exposure. Previously, short-term ( \pm 30 minutes) IVLP resulted in variable efficacy and significant lung toxicity. We hypothesize that a modified IVLP strategy derived from an ex vivo lung perfusion technique could minimize lung injury. Our objective was to demonstrate the feasibility and safety of a modified prolonged (4 hours) IVLP.
\end{abstract}

\begin{abstract}
Methods: Six Yorkshire pigs were used for the experiments. A thoracotomy was performed, the left pulmonary artery and pulmonary veins were cannulated, and the left lung was isolated in situ. IVLP was performed at normothermia for 4 hours using Steen Solution (XVIVO Perfusion, Göteburg, Sweden) as perfusate. The flow rate was $16 \%$ of estimated cardiac output and left atrial pressure was maintained between 3 and $5 \mathrm{~mm}$ $\mathrm{Hg}$. Perfusate was deoxygenated and supplied with $\mathrm{CO}_{2}$ to physiologic levels before entering the lungs. A protective mode of ventilation was used. After IVLP, the left lung was allowed to reperfuse for additional 4 hours. Airway dynamics, gas exchange, and pulmonary vascular resistance were used to assess left lung physiology. Histologic signs of lung injury were assessed before and after IVLP, and 4 hours after reperfusion.
\end{abstract}

Results: Lung function parameters were stable throughout the 4-hour IVLP and during reperfusion. No significant histologic evidence of acute lung injury was observed.

Conclusions: Four hours of IVLP is feasible without adding significant lung injury. Prolonged perfusion time and a protective protocol might provide safer and more efficacious treatment of pulmonary metastases. (J Thorac Cardiovasc Surg 2014;147:774-82)

Lungs can often be the only sites of dissemination of metastases, and this is especially common for neoplasms such as sarcomas and colorectal carcinomas. Lung metastasectomy remains the most effective approach in this situation; however, the 5-year survival of $20 \%$ to $40 \%$ associated with this treatment is disappointing. ${ }^{1}$ One of the most important factors related to this poor overall survival is the intrathoracic recurrence of resected disease, which is common. ${ }^{2,3}$ The presence of micrometastatic disease may be correlated with this local recurrence and in many cases

From the Latner Thoracic Surgery Laboratories, ${ }^{\text {a }}$ Toronto General Research Institute, University Health Network, Toronto, Ontario, Canada; and Department of Surgery, ${ }^{\text {b }}$ Institute of Medical Science, University of Toronto, Toronto, Ontario, Canada.

M. Cypel was supported by an AATS Michael E. DeBakey Research Grant and T.K. Waddell was supported by a Princess Margaret Innovation Grant. XVIVO Perfusion (Göteburg, Sweden) supported this research by providing Steen Solution and disposables for in vivo lung perfusion.

Disclosures: Authors have nothing to disclose with regard to commercial support.

Read at the 92nd Annual Meeting of The American Association for Thoracic Surgery, San Francisco, California, April 28-May 2, 2012.

Received for publication Aug 6, 2013; revisions received Sept 19, 2013; accepted for publication Oct 6, 2013; available ahead of print Dec 2, 2013.

Address for reprints: Marcelo Cypel, MD, MSc, Division of Thoracic Surgery, University of Toronto, Toronto General Hospital, 200 Elizabeth St 9N969,

Toronto, Ontario M5G2C4, Canada (E-mail: marcelo.cypel@uhn.ca).

0022-5223/\$36.00

Copyright (c) 2014 by The American Association for Thoracic Surgery

http://dx.doi.org/10.1016/j.jtcvs.2013.10.009 is not properly treated because it cannot be noticed during surgery. The delivery of high-dose chemotherapy exclusively to the lung within a closed system, via in vivo lung perfusion (IVLP), can be an attractive strategy to overcome this problem. IVLP allows for the selective delivery of therapy to the lungs, avoiding the systemic side effects associated with drug administration while achieving high concentrations of chemotherapy in the lung tissue.

Past clinical studies presented significant toxicity to the lungs, including acute complications (noncardiogenic lung edema and chemical pneumonitis) and chronic alterations (decreased forced expiratory volume in 1 second and diffusion capacity), and these were important factors that limited the widespread use of this approach. ${ }^{4-6}$ It was unclear from many of these studies whether the perfusion procedure itself or the chemotherapy was the major reason for the lung injury. Improved lung perfusion technology and strategies have been described recently, especially for lung transplantation. Based on our previous experience with ex vivo lung perfusion (EVLP), lungs can now be perfused and ventilated for several hours at normothermic temperatures without inflicting lung injury. ${ }^{7}$ With the knowledge learned from EVLP, we aimed to develop a novel IVLP strategy to be used safely as a platform for the local delivery of treatment strategies for the prevention of pulmonary metastases recurrences. 

Abbreviations and Acronyms
$\mathrm{EVLP}=$ ex vivo lung perfusion
IVLP $=$ in vivo lung perfusion
LA $=$ left atrium
PA = pulmonary artery
PawP $=$ peak airway pressure
$\mathrm{PVR}=$ pulmonary vascular resistance

\section{METHODS}

\section{Animals}

Six Yorkshire pigs weighing an average of $35 \mathrm{~kg}$ were used for all experiments. All animals received humane care in compliance with the Principles of Laboratory Animal Care formulated by the National Society for Medical Research and the Guide for the Care of Laboratory Animals published by the National Institutes of Health. The Animal Care Committee of the Toronto General Research Institute approved this study.

\section{Experimental Strategy}

Animals were subjected to a 4-hour period of left lung IVLP followed by a single-pass gravity-driven washout and additional 4 hours of reperfusion. Ventilation and perfusion parameters were derived and modified from the EVLP technique and are described in Table 1. At the end of reperfusion, the animals were killed by exsanguination.

\section{IVLP Procedure}

After induction of general anesthesia, a tracheostomy was performed and a 19-Fr left-sided double-lumen endotracheal tube was positioned to allow measurement of the airway mechanics of the perfused lung throughout the procedure. Ventilation was maintained with an intensive care unit ventilator (Servo-I; Maquet Critical Care, Solna, Sweden) according to the parameters listed in Table 1. A left posterolateral thoracotomy was performed and the left azygous vein was ligated over the descending aorta, with dissection carried toward the left pulmonary artery (PA), which was fully mobilized. The next step was the mobilization of the upper and lower left pulmonary veins. For this purpose, a dissection plane was created between the left azygous vein and the left atrium (LA). Proper identification of the mediastinal venous branch is important because this facilitates the positioning of the LA clamp. The left main bronchus was then dissected and isolated and the peribronchial tissue was stripped to diminish bronchial circulation in the isolated lung circuit.

After dissection of these structures, 2 concentric purse-string sutures were placed in the left PA and 1 purse-string suture in each left pulmonary vein. Heparin 5000 IU (Sandoz, Quebec City, Canada) was administered through a central venous line and a cannula (Cardioplegia Cannula Antegrade, 13 Fr; Maquet Cardiopulmonary, Rastatt, Germany) was inserted in the PA and snared. A right-angle cannula (Venous Catheter OD $12 \mathrm{Fr}$; Maquet Cardiopulmonary) was then inserted in the upper and lower left pulmonary veins (Figure 1). The venous cannulas were inserted as close as possible to the junction of the pulmonary veins to the LA to prevent selective cannulation of venous branches. Pediatric feeding tubes (5Fr) were used to monitor the pulmonary and LA pressures; the tubes were inserted in the PA and in the left lower vein, respectively, and connected to a monitor (SurgiVet; Smiths Medical, Norwell, Mass). Before IVLP initiation, PA and LA vascular clamps were inserted to isolate the left lung from the systemic circulation.

\section{IVLP Circuit}

The IVLP circuit is shown in Figure 1. The perfusate was circulated by a centrifugal pump (Revolution; Sorin Group USA Inc, Arvada, Colo) passing through a leukocyte depletion filter (LG-6 Leukocyte Reduction Filter; Pall Corporation, Port Washington, NY) and a membrane gas exchanger (Quadrox-i Oxygenator System; Maquet Cardiopulmonary AG, Hirrlingen, Germany) before entering the left lung through the PA. A filtered gas line for the gas exchange membrane was connected to an $\mathrm{H}$-size specialty gas mixture of oxygen $(6 \%)$, carbon dioxide $(8 \%)$, and nitrogen $(86 \%)$ (Praxair, Mississauga, Canada). This mixture deoxygenates the perfusate and provides carbon dioxide to the inflow maintaining $\mathrm{PCO}_{2}$ between 35 and $45 \mathrm{~mm} \mathrm{Hg}$ (the gas was started at $1 \mathrm{~L} / \mathrm{min}$ and was adjusted to obtain these $\mathrm{PCO}_{2}$ levels). A heat exchanger (Sarns, Ann Arbor, Mich) was connected to the membrane gas exchanger to maintain the perfusate at $37^{\circ} \mathrm{C}$. PA flow was controlled by the centrifugal pump and measured using an electromagnetic flow meter (Sorin Group, Munich, Germany). The outflow perfusate was returned through the left atrial cannulas to a hard-shell reservoir (Maquet Cardiopulmonary AG). The height of the reservoir controlled LA pressure.

\section{Priming the Circuit}

The reservoir of the circuit was primed with $1.2 \mathrm{~L}$ of Steen Solution (XVIVO Perfusion, Göteburg, Sweden), which is a buffered dextran containing an extracellular solution with an optimal colloid osmotic pressure, developed for extracorporeal perfusion of lungs. In addition, $500 \mathrm{mg}$ of methyl prednisolone (Solu-medrol; Pfizer, Kirkland, Canada), $1 \mathrm{~g}$ of cefazolin (Pharmaceutical Partners of Canada Inc, Richmond Hill, Canada), and $5000 \mathrm{IU}$ of heparin were added to the perfusate.

\section{Perfusion Strategy}

Perfusion was initiated at $37^{\circ} \mathrm{C}$, with continuous measurement of the systemic, PA, and LA pressures, with a flow established according to the estimated cardiac output of the animal. We used $16 \%$ of estimated cardiac output to perfuse the left lung only. The rationale for this flow rate is that, in the EVLP protocol, we perfuse both lungs with $40 \%$ of the calculated cardiac output. From this value, approximately $60 \%$ of the flow (ie, $24 \%$ of the entire cardiac output) is directed to the right lung and $40 \%$ (ie, $16 \%$ of the cardiac output) to the left lung. Using these calculations, usual flows to the left lung were 450 to $550 \mathrm{~mL} / \mathrm{min}$ depending on animal weight and estimated cardiac output. To obtain these rates, we used a strategy to gradually increase the flow, which consisted of a 3 -step increment starting with $30 \%$ of the calculated flow for 10 minutes, then moving to $60 \%$ for the next 10 minutes, and finally to $100 \%$ (at full IVLP flow). Once PA pressure levels were obtained, we adjusted the reservoir height of the perfusion circuit to maintain LA pressure between 3 and $5 \mathrm{~mm} \mathrm{Hg}$.

\section{Ventilation Strategy for Measurement of Left Lung Function}

During IVLP, oxygenation of the animal was performed by the right lung exclusively. Using a double-lumen endotracheal tube, the right lung was briefly excluded to assess pulmonary mechanics of the left lung only. This was performed every hour during IVLP. After this measurement, ventilation for both lungs was restarted, and a recruitment maneuver to a Pawp of $25 \mathrm{~cm} \mathrm{H}_{2} \mathrm{O}$ was performed to fully reexpand the right lung. It is necessary to carefully control the oxygenation level of the animal because hypoxia may appear promptly during right lung deflation.

\section{Terminating IVLP and the Reperfusion Phase}

After 4 hours of IVLP, venous cannulas were removed and washout was administered in an anterograde fashion with $500 \mathrm{~mL}$ of a low potassium dextran solution (Perfadex; XVIVO Perfusion), positioned $30 \mathrm{~cm}$ above the animal, allowing a passive drainage of the effluent through the left pulmonary veins by gravity. This washout period usually takes 10 to $15 \mathrm{mi}-$ nutes. The purse-string sutures in the pulmonary veins were then tied and the LA and PA clamps were carefully removed. A review of the 
TABLE 1. Ventilatory and perfusion strategies

\begin{tabular}{lc}
\hline Ventilatory parameters & \\
Tidal volume & $8 \mathrm{~mL} / \mathrm{kg}$ \\
PEEP & $5 \mathrm{~cm} \mathrm{H} \mathrm{O}_{2}$ \\
Respiratory rate & $16 \mathrm{breaths} / \mathrm{min}$ \\
$\mathrm{FIO}_{2}$ & $50 \%$ \\
Perfusion parameters & \\
Flow rate & $16 \%$ of cardiac output \\
Pulmonary artery pressure & $10-15 \mathrm{~mm} \mathrm{Hg}$ \\
Left atrium pressure & $3-5 \mathrm{~mm} \mathrm{Hg}$ \\
Temperature of perfusate & $37^{\circ} \mathrm{C}$ \\
\hline
\end{tabular}

PEEP, Positive end-expiratory pressure; $\mathrm{FIO}_{2}$, fraction of inspired oxygen. Parameters adapted from Cypel and colleagues. ${ }^{7}$

operative field was performed, and any possible source of bleeding was identified and fixed. The pressure monitor catheters were left in place for measurement of PA pressure in the reperfusion period and to collect samples from the lower lobe vein.

\section{Lung Function Assessments}

Lung function was assessed before IVLP, hourly during IVLP, and after reperfusion. Gas exchange function $\left(\mathrm{PaO}_{2} / \mathrm{FIO}_{2}\right)$ using samples collected from the left lower vein (before IVLP and during reperfusion) and from the outflow of the perfusion circuit (during IVLP), airway dynamics (airway peak and plateau pressures), lung compliance (static and dynamic), and pulmonary vascular resistance (PVR) ([PA pressure - LA pressure $] \times 80 /$ PA flow $\left[\mathrm{dyn} / \mathrm{s} / \mathrm{cm}^{5}\right]$ ) were evaluated. Gas exchange, PVR, peak airway pressure (PawP), and dynamic compliance were recorded from both lungs, as well as from the perfused lung only.

\section{Histology}

Lung tissue biopsies were collected from the periphery of the lung before and after IVLP, and 4 hours after reperfusion. Tissue samples were fixed in $10 \%$ buffered formalin for 48 hours before being transferred to $70 \%$ alcohol solution, embedded in paraffin, sectioned at $5-\mu \mathrm{m}$ thickness, stained by hematoxylin and eosin, and examined for pathologic changes under light microscopy. The following criteria were used to obtain the pathologic acute injury score: air space hemorrhage (presence of red blood cells in the alveoli), vascular congestion ( $>75 \%$ of alveolar septum occupied by red blood cells), fibrin in the alveoli, and the presence of infiltrating white blood cells. These criteria were graded on a scale ranging from normal appearance $(0 \%)$, mild $(10 \%)$, moderate $(10 \%-50 \%)$, and severe $(>50 \%)$ abnormalities and scored from 0 to 3 , respectively.

Radiologic assessment of the perfused lung, comparing values before IVLP and at the end of the experiment, was used to assess for possible signs of acute lung injury such as pulmonary infiltrates.

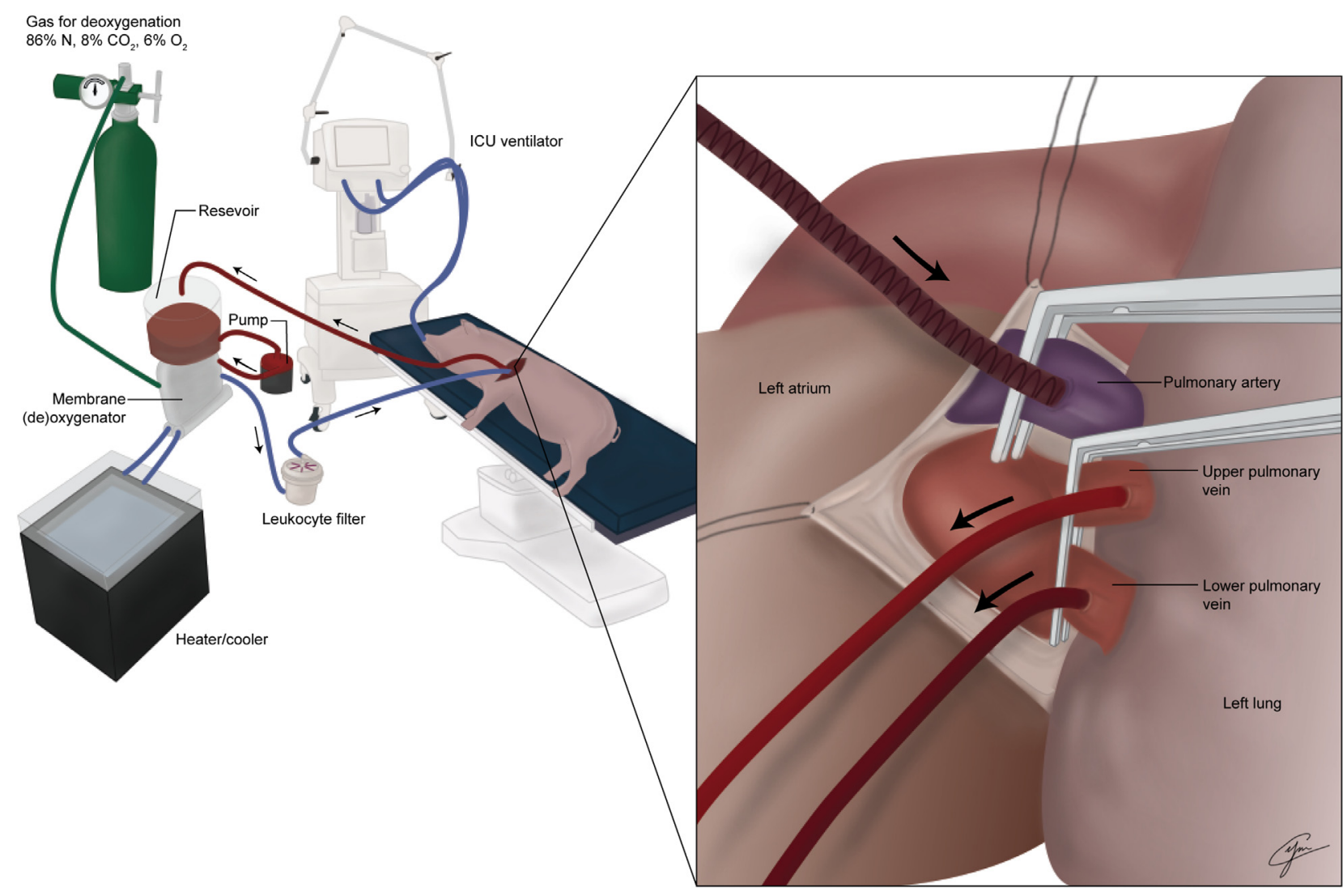

FIGURE 1. Perfusion circuit. The perfusate is circulated by a centrifugal pump passing through a membrane gas exchanger, which receives a combination of gas (oxygen, $6 \%$; carbon dioxide, $8 \%$; and nitrogen, $86 \%$ ) to deoxygenate the perfusate and provide $\mathrm{CO}_{2}$ for the inflow. Flow is then directed to a leukocyte filter and enters the lung through the left pulmonary artery. The temperature of the perfusate is maintained using a heat exchanger, which is connected to the membrane gas exchanger. Pulmonary artery flow is controlled by the centrifugal pump and measured using an electromagnetic flow meter. The outflow perfusate returns through the left pulmonary veins to a hard-shell reservoir, and the height of this reservoir is adjusted to have the drainage pressure within the appropriate range. Catheters in the left pulmonary artery and in the left lower vein measure PA and LA pressures, respectively. A standard intensive care unit $(I C U)$ ventilator provides ventilation to the lungs. 

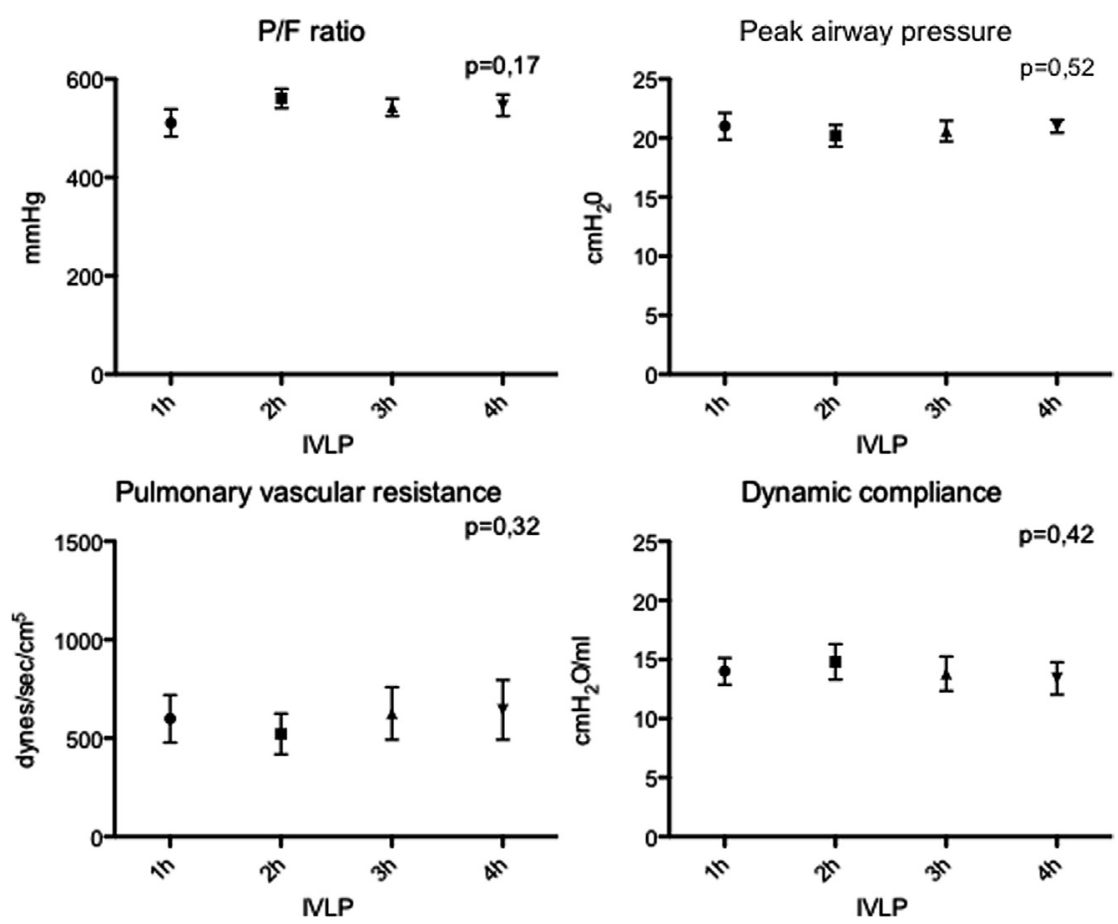

FIGURE 2. Left lung function during in vivo lung perfusion (IVLP). Lung function remained stable throughout the IVLP period. Lung oxygenation function $\left(\mathrm{P} / \mathrm{F}\right.$ ratio, in $\mathrm{mm} \mathrm{Hg}$ ), pulmonary vascular resistance (in dyn/s/ $/ \mathrm{cm}^{5}$ ), peak airway pressure (in $\mathrm{cm}_{2} \mathrm{O}$ ), and dynamic compliance (in $\left.\mathrm{mL} / \mathrm{cm} \mathrm{H}_{2} \mathrm{O}\right)$ all remained stable from 1 hour to 4 hours of IVLP $(\mathrm{n}=6 ; P>.05$ between measures of lung function at all time points during IVLP, using repeated measures analysis of variance).

\section{Statistical Analysis}

Results were analyzed using GraphPad Prism 5 (GraphPad Software Inc, La Jolla, Calif). Data are expressed as mean \pm standard error of the mean. For comparisons of lung ventilatory and perfusion parameters, repeated measures analysis of variance was used. Posttest analysis between each time point was performed with the Tukey test for multiple comparisons. For comparisons between pathologic injury scores, the Kruskal-Wallis test was used, and posttest analysis was performed using the Dunn test.

\section{RESULTS}

The gas exchange (P/F ratio), PVR, and airway dynamics (PawP and dynamic compliance) for the left lung remained stable during 4-hour IVLP. The left lung had excellent oxygenation levels during IVLP (P/F ratio was $510.8 \pm$ $27.79 \mathrm{~mm} \mathrm{Hg}$ at 1 hour and $546.4 \pm 21.77 \mathrm{~mm} \mathrm{Hg}$ at 4 hours; $P=.17)$ and no significant increase in PVR during the IVLP was observed (PVR was $1.401 \pm 352.9 \mathrm{dyn} / \mathrm{s} / \mathrm{cm}^{5}$ at 1 hour and $1.516 \pm 435.2 \mathrm{dyn} / \mathrm{s} / \mathrm{cm}^{5}$ at 4 hours; $P=.941$ ) (Figure 2). The P/F ratio in the left lower pulmonary vein before IVLP was $325.2 \pm 24.45 \mathrm{~mm} \mathrm{Hg}$ and at the end of the procedure ( 4 hours IVLP +4 hours of blood reperfusion), the $\mathrm{P} / \mathrm{F}$ ratio was $433 \pm 37.42 \mathrm{~mm} \mathrm{Hg}$ $(P=.17)$. The PawP and the dynamic compliance of the left lung remained stable during IVLP and reperfusion (Figure 3). Gas exchange, airway dynamics, and PVR of both lungs did not show any differences throughout the procedure and are not described here.
There were no differences in histologic acute lung injury scores for 3 time points; representative images and scores are shown in Figure 4. Chest radiographs at the beginning of the procedure and at the end of 4 hours IVLP and the additional 4 hours of reperfusion showed similar radiographic patterns in the left lung, with no radiographic signs of acute lung injury (Figure 5).

\section{DISCUSSION}

A successful strategy of IVLP for an extended period of time without inflicting lung injury is described here. This approach could potentially be used to lower the odds of local recurrence after lung metastasectomy by administering high-dose chemotherapy or targeted drug therapy to the lung without deleterious systemic side effects.

The IVLP approach has been used recently with encouraging results in a clinical setting ${ }^{8}$; a phase 1 clinical study was performed using short-term (30 minutes) IVLP with melphalan for resectable lung metastases from tumors such as colorectal, kidney and sarcomas. Although lung function was impaired at 1 month of follow-up, no major long-term toxicity was found. It is important to note that lung metastasectomy with IVLP could be performed with results comparable with conventional lung metastasectomy regarding postoperative quality of life scores. ${ }^{9}$

In the past 2 decades, experimental and clinical studies on IVLP have shown the feasibility and reproducibility of 

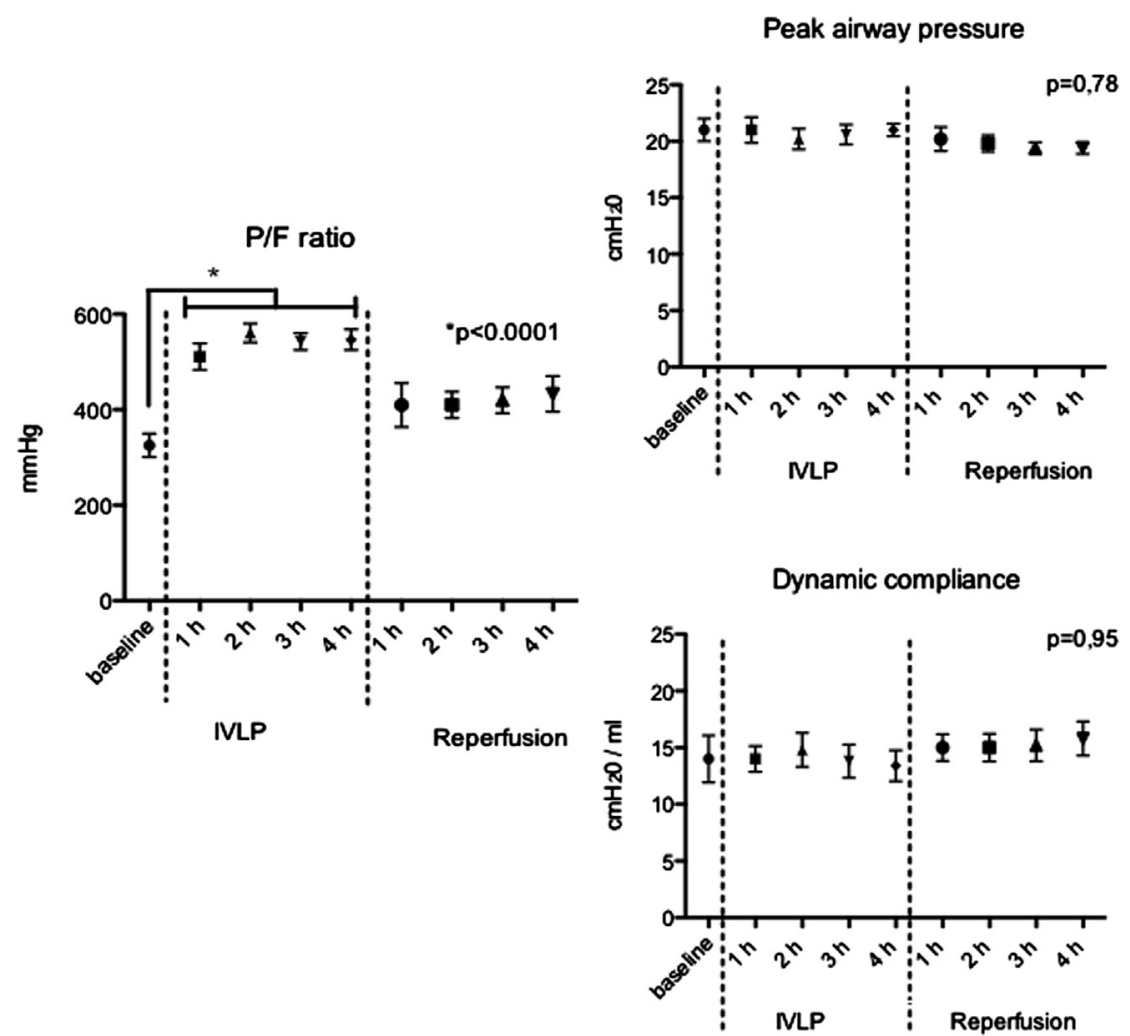

FIGURE 3. Left lung function after reperfusion. Compared with the baseline level, optimal oxygenation ( $P / F$ ratio $)$ was found during in vivo lung perfusion $(I V L P)$ and after reperfusion. Peak airway pressure and dynamic compliance were also stable after reperfusion.

this modality as a potential treatment of pulmonary metastases. ${ }^{10}$ Higher tissue concentrations were found with this approach compared with systemic administration of chemotherapy, ${ }^{11}$ and further experiments showed that IVLP was effective in the treatment of lung metastases in small animal models. ${ }^{12,13}$ However, despite the initial optimism that was generated with these research experiments, the subsequent clinical studies using shortterm IVLP to evaluate different drugs (doxorubicin, cisplatin, and melphalan) and perfusate solutions (saline, colloids, dextran, and blood) raised important concerns with regard to acute lung toxicity and no improvement in overall survival, ${ }^{5,14}$ hindering the broad application of this technique. Most of these studies did not state whether the toxicity was mainly related to the drug, perfusion solution, or technique of IVLP applied.

Our study aim was to demonstrate that no measurable lung injury occurs with this new IVLP strategy. Previous large-animal studies have raised concerns about the potential injury that the perfusion system may inflict apart from the chemotherapeutic agent. Furrer and colleagues ${ }^{15}$ performed IVLP for 15 minutes in pigs, using flows ranging from 70 to $120 \mathrm{~mL} / \mathrm{min}$, and found that controls animals (IVLP without chemotherapy) had the same pattern of acute lung injury in histology and chest radiographs compared with animals perfused with doxorubicin. In another study, pigs submitted to IVLP with and without chemotherapy demonstrated higher histologic injury scores and impairment of functional parameters compared with a sham group. ${ }^{16}$ Histologic signs of hemorrhagic edema were found in both the control and melphalan-treated groups, ${ }^{17}$ raising the question of the potential role that the perfusion circuit may have in causing injury. More recently, Pages and colleagues $^{18}$ performed IVLP for 30 minutes in $50-\mathrm{kg}$ pigs, with a perfusion flow that ranged from 500 to 600 $\mathrm{mL} / \mathrm{min}$ (adjusted to a PA pressure of around $25 \mathrm{~mm} \mathrm{Hg}$ ) and found that the control group had even greater histologic injury compared with lungs perfused with gemcitabine. This again highlights that IVLP itself without drugs was injurious.

With the objective to optimize previously reported IVLP techniques, we derived many technical aspects from the EVLP technique described by our group to preserve lungs for extended periods outside the body, allowing for repair and recovery of lung function for transplantation. The clinical efficacy of the EVLP technique has already been proved. ${ }^{19}$

Some key aspects of this modified IVLP technique include

1. A perfusate solution with optimal osmotic pressure designed specifically for lung perfusion. This is a 

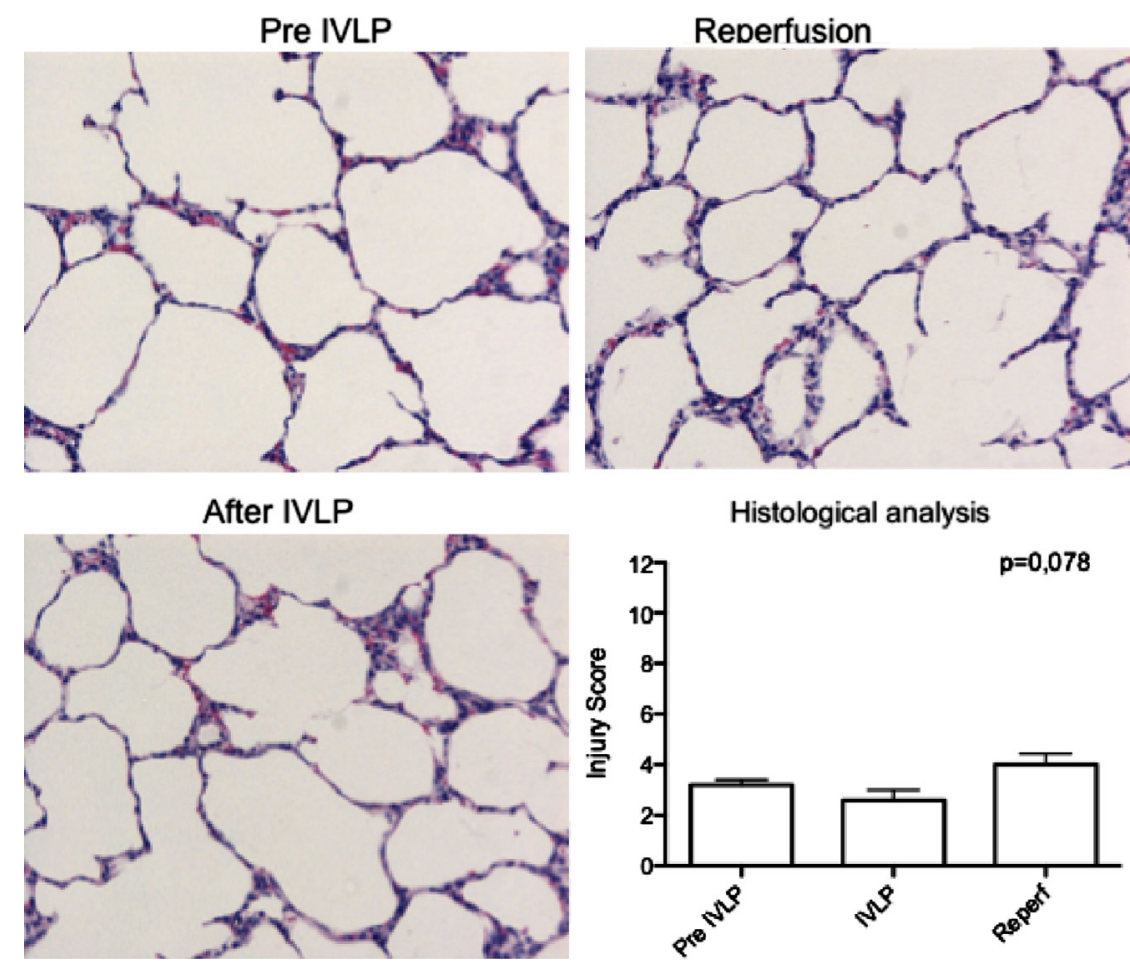

FIGURE 4. Histologic appearance of the lung before in vivo lung perfusion (IVLP), after prolonged IVLP, and after the additional 4 hours of reperfusion. Lung histology was preserved at all time points. Injury score analyzed the presence of air space hemorrhage, vascular congestion, fibrin in the alveoli, and infiltrating white blood cells. Each criterion was graded with a scale ranging from normal appearance $(0 \%)$, mild $(10 \%)$, moderate $(10 \%-50 \%)$, and severe $(>50 \%)$ abnormalities and scored from 0 to 3 , respectively.

solution with high dextran content and albumin, leading to optimal osmolality and oncotic pressure, and preventing the development of extravasation of intravascular fluid to the interstitium and alveolar space. This solution cleared pulmonary edema in injured donor lungs, demonstrating its excellent properties for lung perfusion. Previous and currently used solutions for IVLP (saline solution, colloid solutions, blood) do not have the same characteristics and have already been shown to induce pulmonary edema in different animal models of lung perfusion. ${ }^{20,21}$

2. A perfusion flow that reduces hydrostatic pressure, diminishing the chance of lung edema development. In accordance with our previous studies with EVLP, we

\section{Pre IVLP}

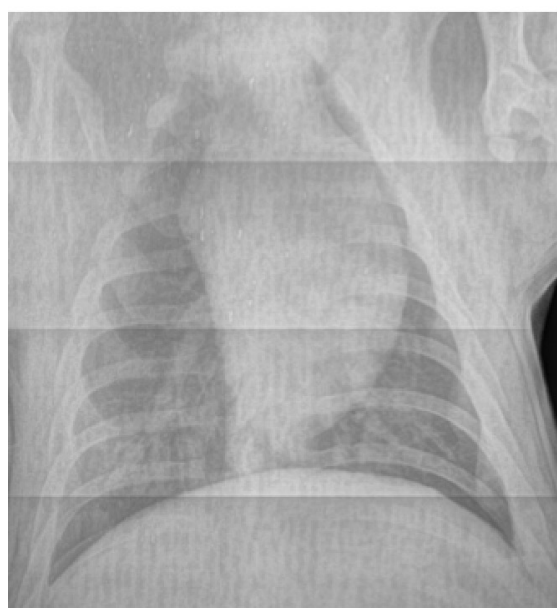

Post $4 \mathrm{~h}$ IVLP $+4 \mathrm{~h}$ Reperfusion

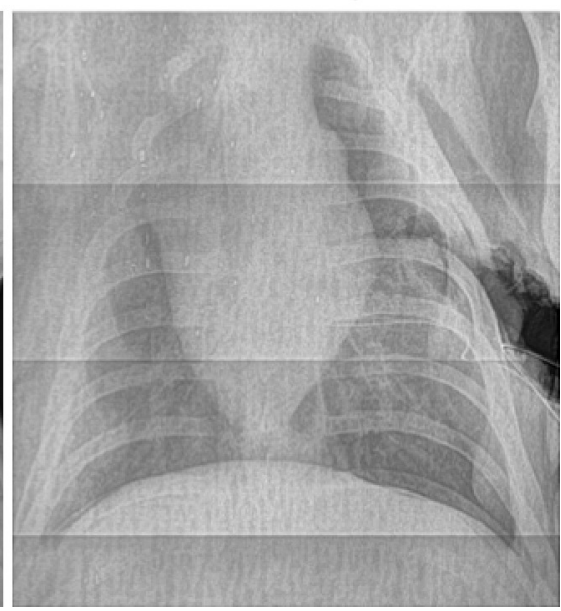

FIGURE 5. Chest radiograph comparing lungs before in vivo lung perfusion $(I V L P)$ and at the end of 4 hours of IVLP +4 hours of reperfusion showed a preserved pattern in the left lung without signs of acute lung injury. 
perfused the left lung with $16 \%$ of cardiac output. This rendered a PA pressure of 10 to $15 \mathrm{~mm} \mathrm{Hg}$, which is much lower than that described in other IVLP techniques in which, most of the time, the flow is increased until the PA pressure reaches 20 or $25 \mathrm{~mm} \mathrm{Hg}$. By maintaining a lower hydrostatic pressure, the pulmonary vasculature is protected. Steen and colleagues ${ }^{22}$ have used a PA pressure of $20 \mathrm{~mm} \mathrm{Hg}$ for EVLP and they have recognized that after 1 hour of EVLP, pulmonary edema starts to appear. In contrast, our studies have shown no edema development for up to 12 hours of perfusion. ${ }^{7}$ Despite this low-pressure strategy, we did achieve homogeneous distribution of perfusion over time. The linear relationship between perfusion flows, PA pressure levels, and the development of pulmonary edema is well known ${ }^{23}$; thus, our flow rates, between 450 and $550 \mathrm{~mL} / \mathrm{min}$ under PA pressure levels of 10 to $15 \mathrm{~mm} \mathrm{Hg}$, may have an important role in protecting the lungs.

3. A positive and physiologic LA pressure preventing a collapse and reopening phenomenon, and protecting the vascular endothelium. Although previous descriptions of IVLP models had controlled PA pressures, they did not exert any control over the drainage pressure in the pulmonary veins (drainage pressure). The system described here drains the effluent to a hard-shell reservoir where the drainage pressure can be perfectly controlled and kept at physiologic levels of 3 to $5 \mathrm{~mm}$ $\mathrm{Hg}$. We believe this is an important element to protect the lungs. Many physiologic experiments have been performed demonstrating that either negative pressures or supraphysiologic LA pressures induce pulmonary edema and vascular failure. ${ }^{24,25}$

4. Protective mechanical ventilation with lower tidal volumes, which prevent increases in alveolar perivascular pressure that can lead to an increase in PVR and lung injury. $^{26}$

5. A mean PA pressure within a range as close as possible to physiologic levels (10-15 $\mathrm{mm} \mathrm{Hg}$ ), because increases in the PA pressure levels may correlate with acute lung injury in isolated lung perfusion. ${ }^{27}$ Some factors other than pump flow may influence the PA pressure levels, such as a low $\mathrm{pH}$ in the perfusate, the presence of high tidal volumes, impaired left atrial drainage, and technical problems with the catheters measuring these pressures. All these factors must be corrected to have a stable and reliable PA pressure throughout the procedure.

6. The use of a centrifugal pump with better protection of lung vasculature.

7. The use of a membrane gas exchanger supplied with a special mixture of gas to maintain the physiologic levels of $\mathrm{CO}_{2}$ in the perfusate, which has been shown to be an important component of lung protection. $^{28}$
During the development of this IVLP large-animal model, some important intraoperative technical factors were identified:

- Proper position of vascular clamps: considering the small dimensions of the cannulas used to cannulate the left PA and the pulmonary veins, a clamp that is not in the proper position may generate obstruction or malfunctioning of these cannulas, leading to high levels of PA and LA pressure.

- Adequate drainage of the left pulmonary veins: it is important to dissect and properly isolate the left pulmonary veins. The dissection should be carried toward the LA, which is a proper site to anchor the purse-string sutures. A well-placed cannula (as close as possible to the junction of the atrium and the respective vein) is the best way to avoid obstruction of the outflow drainage, allowing optimal drainage pressures.

- Bronchial circulation: important systemic flow is drained to the reservoir during extended periods of IVLP and this may lead to instability of the hemodynamic status of the animal. Careful cauterization of these vessels around the left main bronchus and snaring of the bronchus if a left-side double-lumen tube is used must be done to achieve complete isolation of this circulation to the left lung.

The limitations of this study are the absence of other groups with different perfusion strategies for comparison and the absence of long-term follow-up. Although the 4-hour perfusion time may seem long for clinical application, pharmacokinetics studies are now being performed with different drugs to determine the potential advantages of a prolonged perfusion time on tissue concentration and distribution in this model. Experimental studies in small animals have demonstrated that increased levels of chemotherapy in lung tissue were found with increases in IVLP time. ${ }^{29}$ IVLP with a safe extended perfusion time may also open up opportunities for other localized therapies that require a longer exposure window such as gene therapy. ${ }^{30}$

In conclusion, this modified IVLP technique can be performed safely, without evidence of acute lung injury. Studies on the use of chemotherapy using the strategy described here need to be performed. Some concepts that were previously studied within an isolated lung perfusion setting may be reevaluated in the future using this platform, such as hyperthermic perfusion and multidrug medical regimens. A reliable platform to perfuse an organ in situ without inflicting damage may be an important step toward the use of more efficacious conventional chemotherapy, targeted therapies, or gene therapy aiming to prevent recurrence or treat lung metastases. The results derived from these studies will set the stage to establish a clinical IVLP program at our institution. 
The authors would like to thank Paul Chartrand for organizing the logistics and the Perfusion Team of the Hospital for Sick Children and Toronto General Hospital for their expert advice. The authors are grateful to Yi-Min Chun for her excellent illustration done for this manuscript.

\section{References}

1. Pastorino U, Buyse M, Fryedel G, Ginsberg RJ, Girard P, Goldstraw P, et al. Long-term results of lung metastasectomy: prognostic analyses based on 5206 cases. The International Registry of Lung Metastases. J Thorac Cardiovasc Surg. 1997;113:37-49.

2. Billingsley KG, Burt ME, Jara E, Ginsberg RJ, Woodruff JM, Leung DH, et al. Pulmonary metastases from soft tissue sarcoma: analysis of patterns of diseases and postmetastasis survival. Ann Surg. 1999;229:602-10; discussion 610-12.

3. McCormack PM, Burt ME, Bains MS, Martini N, Rusch VW, Ginsberg RJ. Lung resection for colorectal metastases: 10-year results. Arch Surg. 1992;127: 1403-6.

4. Burt ME, Liu D, Abolhoda A, Ross HM, Kaneda Y, Jara E, et al. Isolated lung perfusion for patients with unresectable metastases from sarcoma: a phase I trial. Ann Thorac Surg. 2000;69:1542-9.

5. Putnam JB. New and evolving treatment methods for pulmonary metastases. Semin Thorac Cardiovasc Surg. 2002;14:49-56.

6. Schröder C, Fisher S, Pieck AC, Müller A, Jaehde U, Kirchner H, et al. Technique and results of hyperthermic $\left(41^{\circ} \mathrm{C}\right)$ isolated lung perfusion with high-doses of cisplatin for the treatment of surgically relapsing or unresectable lung sarcoma metastasis. Eur J Cardiothorac Surg. 2002;22:41-6.

7. Cypel M, Yeung JC, Hirayama S, Rubacha M, Fischer S, Anraku M, et al. Technique for prolonged normothermic ex vivo lung perfusion. J Heart Lung Transplant. 2008;27:1319-25.

8. Hengst Den WA, Van Putte BP, Hendriks JMH, Stockman B, Van Boven W-JP, Weyler J, et al. Long-term survival of a phase I clinical trial of isolated lung perfusion with melphalan for resectable lung metastases. Eur J Cardiothorac Surg. 2010;38:621-7

9. Balduyck B, Van Thielen J, Cogen A, Hengst Den W, Hendriks J, Lauwers P, et al. Quality of life evolution after pulmonary metastasectomy: a prospective study comparing isolated lung perfusion with standard metastasectomy. J Thorac Oncol. 2012;7:1567-673.

10. Johnston MR, Minchen RF. Lung perfusion with chemotherapy in patients with unresectable metastatic sarcoma to the lung or diffuse bronchioloalveolar carcinoma. J Thorac Cardiovasc Surg. 1995;110:1-6.

11. Weksler B, Bruce N, Lenert JT, Burt ME. Isolated single-lung perfusion with doxorubicin is pharmacokinetically superior to intravenous injection. Ann Thorac Surg. 1993;56:209-14.

12. Weksler B, Lenert J, Ng B, Burt M. Isolated single lung perfusion with doxorubicin is effective in eradicating soft tissue sarcoma lung metastases in a rat model. J Thorac Cardiovasc Surg. 1994;107:50.

13. Weksler B, Blumberg D, Lenert JT, Ng B, Fong Y, Burt ME. Isolated single-lung perfusion with TNF- $\alpha$ in a rat sarcoma lung metastases model. Ann Thorac Surg. 1994;58:328-32.

14. Hendriks JMH, Grootenboers MJJH, Schramel FMNH, Van Boven WJ, Stockman B, Seldenrijk CA, et al. Isolated lung perfusion with melphalan for resectable lung metastases: a phase I clinical trial. Ann Thorac Surg. 2004;78: 1919-27.

15. Furrer M, Lardinois D, Thormann W, Altermatt HJ, Betticher D, Cerny T, et al. Isolated lung perfusion: single-pass system versus recirculating blood perfusion in pigs. Ann Thorac Surg. 1998;65:1420-5.

16. Franke UF, Wittwer T, Kaluza M, Albert M, Becker V, Roskos M, et al. Evaluation of isolated lung perfusion as neoadjuvant therapy of lung metastases using a novel in vivo pig model: II. High-dose cisplatin is well tolerated by the native lung tissue. Eur J Cardiothorac Surg. 2004;26:800-6.

17. Van Der Elst A, Oosterling SJ, Paul MA, Vonk AMA, Sparidans RW, van der Sijp JRM. Isolated lung perfusion with melphalan: pharmacokinetics and toxicity in a pig model. J Surg Oncol. 2006;93:410-6.

18. Pagès P-B, Facy O, Mordant P, Ladoire S, Magnin G, Lokiec F, et al. Isolated lung perfusion as an adjuvant treatment of colorectal cancer lung metastases: a preclinical study in a pig model. PLoS ONE. 2013;8:e59485.

19. Cypel M, Yeung JC, Liu M, Anraku M, Chen F, Karolak W, et al. Normothermic ex vivo lung perfusion in clinical lung transplantation. N Engl J Med. 2011;364: 1431-40.
20. Veith FJ, Hagstrom JW, Nehlsen SL, Karl RC, Deysine M. Functional, hemodynamic, and anatomic changes in isolated perfused dog lungs: the importance of perfusate characteristics. Ann Surg. 1967;165:267-78.

21. Fisher AB, Dodia C, Linask J. Perfusate composition and edema formation in isolated rat lungs. Exp Lung Res. 1980;1:13-21.

22. Steen SS, Liao QQ, Wierup PNP, Bolys RR, Pierre LL, Sjöberg TT. Transplantation of lungs from non-heart-beating donors after functional assessment ex vivo. Ann Thorac Surg. 2003;76:244-52.

23. McLean RF, Noble WH, Kolton M. Pulmonary pressures at high flows in the intact pulsatile flow perfused lung. Can J Anaesth. 1992;39:381-6.

24. Peták F, Habre W, Hantos Z, Sly PD, Morel DR. Effects of pulmonary vascular pressures and flow on airway and parenchymal mechanics in isolated rat lungs. J Appl Physiol. 2002;92:169-78.

25. Georgieva GS, Kurata S, Ikeda S, Teng S, Katoh I, Eishi Y, et al. Prevention of ischemia reperfusion injury by positive pulmonary venous pressure in isolated rat lung. Shock. 2006;25:66-72.

26. Petrucci N, De Feo C. Lung protective ventilation strategy for the acute respiratory distress syndrome. Cochrane Database Syst Rev. 2013;2:CD003844.

27. Franke U, Wittwer T, Lessel M, Liebing K, Albert M, Becker V, et al. Evaluation of isolated lung perfusion as neoadjuvant therapy of lung metastases using a novel in vivo pig model: I. Influence of perfusion pressure and hyperthermia on functional and morphological lung integrity. Eur J Cardiothorac Surg. 2004;26:792-9.

28. Myrianthefs PMP, Briva AA, Lecuona EE, Dumasius VV, Rutschman DHD Ridge KMK, et al. Hypocapnic but not metabolic alkalosis impairs alveolar fluid reabsorption. Am J Respir Crit Care Med. 2005;171:1267-71.

29. Weksler B, Ng B, Lenert JT, Burt ME. Isolated single-lung perfusion: a study of the optimal perfusate and other pharmacokinetic factors. Ann Thorac Surg. 1995; 60:624-9.

30. van Etten B, Eggermont AMM, van Tiel ST, Ambagtsheer G, de Wilt JHW, Hagen ten TLM. Gene therapy in in vivo isolated perfusion models Curr Gene Ther. 2005;5:195-202.

\section{Discussion}

Dr Paul E. Van Schil (Antwerp, Belgium). I would like to thank the Association for the privilege of discussing this excellent paper and I thank the authors for sending me the slides in advance.

Isolated lung perfusion is an experimental technique to deliver high-dose chemotherapy to the lung without systemic exposure in order to obtain better drug targeting. A lot of experimental and, recently, also clinical studies have been performed to evaluate toxicity, pharmacokinetics, and efficacy. In fact, 1 of the first clinical studies originated from Toronto, performed by Michael Johnston, and published in 1995 in the Journal of Thoracic and Cardiovascular Surgery. It is stimulating to see that the Toronto group, having extensive experience with ex vivo lung perfusion, has picked up experimental in vivo lung perfusion studies again. The authors are to be congratulated for performing a difficult experimental study. In our current clinical phase 2 study, which we perform together with 3 thoracic surgical centers in The Netherlands, a dose of $45 \mathrm{mg}$ of melphalan is used with a perfusion time of 30 minutes. In the present experimental study, the authors demonstrate that in a pig model, perfusion times up to 4 hours are feasible without any significant lung injury.

I have several questions for the authors and I will list them separately. Why did you specifically choose Steen solution to perform the lung perfusion, which is rarely used in clinical in vivo perfusion studies, in contrast to transplantation?

Dr dos Santos. We used Steen solution because it is a solution specially developed for lung perfusion and, because of the increased oncotic pressure, it keeps the water in the intravascular space and avoids lung edema. 
Dr Van Schil. Did you temporarily occlude the arterial bronchial circulation during perfusion?

Dr dos Santos. Yes. We try to dissect the bronchial circulation as much as we can, because we noticed that if you do not dissect and try to ligate these vessels, you are going to have a significant leak from the bronchial circulation into the pulmonary circulation and consequently to the circuit, and this might lead to hemodynamic instability.

Dr Van Schil. Regarding the lung injury, how were the different scores determined with a range from 0 to 12 , and was this a validated score?

Dr dos Santos. It is an injury score used by our pathologists at Toronto General Hospital. I'm sorry, I don't understand the question.
Dr Van Schil. Regarding the lung injury, you make a distinction between scores from 0 to 12 . Was this a validated score? We are very interested in that because we do not have a good scoring system for lung injury during perfusion.

Dr dos Santos. My feeling is that it is a validated score, because it is the same score that we have used for many acute lung injury studies done in our institution. I hope that I'm answering your question.

Dr Van Schil. Lastly, perfusion was done at normothermia. Do you have any data on hyperthermic perfusion?

Dr dos Santos. We know that hyperthermia might increase the uptake of drugs, and probably this is 1 variable that we are planning for future studies.

Dr Van Schil. Thank you. 